\title{
Editorial
}

\section{Introduction of newer vaccines in national immunization programme in India: a challenge}

\author{
Ramesh Verma $^{1}$, Vinod Chayal ${ }^{1 *}$, Meenakshi Kalhan', Rohit Dhaka1, \\ Suraj Chawla ${ }^{2}$, Kapil Bhalla ${ }^{3}$
}

\begin{abstract}
${ }^{1}$ Department of Community Medicine, ${ }^{3}$ Department of Pediatric, Pandit Bhagwat Dayal Sharma Post Graduate Institute of Medical Sciences, Rohtak, Haryana, India

${ }^{2}$ Department of Community Medicine, SHKM Government Medical College, Nalhar, Haryana, India
\end{abstract}

Received: 16 February 2020

Accepted: 30 March 2020

*Correspondence:

Dr. Vinod Chayal,

E-mail: drvinodchayal@gmail.com

Copyright: (C) the author(s), publisher and licensee Medip Academy. This is an open-access article distributed under the terms of the Creative Commons Attribution Non-Commercial License, which permits unrestricted non-commercial use, distribution, and reproduction in any medium, provided the original work is properly cited.

The Government of India considered immunization of children is one of the most cost-effective public health interventions. Even now, vaccine preventable diseases (VPDs) are causing over 5 lakh children deaths per year and all these children could be saved simply by immunization. Vaccination significantly decreases the incidence of communicable diseases especially the VPDs and its adverse health consequences that in turn improves the quality and longevity of life of children. ${ }^{1,2}$ Many developing countries are lagging behind in sufficient coverage of routine immunization (RI). According to national family heath survey $(2015-16), 62 \%$ children in India were fully immunized. In the United States, costbenefit analysis indicates that one dollar invested in a vaccine dose saves US\$ 2 to US\$ 27 in health expenses. ${ }^{3}$

The communicable diseases are more common in the most of developing countries like India which indicates that there is need of hour to invest more into research for the newer vaccines. Most of vaccines which are of lowcost are now manufactured in India. Currently, India is manufacturing about $43 \%$ of the global Universal Immunization Programme (UIP) vaccines. ${ }^{4}$ Newer vaccine research can only be promoted when there is good working environment, funding and chances of vaccine being introduced in the UIP. Government of India has its own vaccine policy in the name of National Vaccine Policy (NVP) which was developed after the recommendations made by National Technical Advisory Group on Immunization (NTAGI). The NVP address many issues to streamline the guidelines for making the new and underutilized vaccine and suggests to strengthen the evidence base and institutional framework required for strengthening the UIP in India. ${ }^{5}$

\section{Criteria for introduction of newer vaccines ${ }^{6}$}

Identifying vaccines of local relevance: Introduction of newer vaccine depends upon the disease burden in the country. This information, regarding the burden of diseases may be collected from previous researches, modeling studies or data may be taken from the countries have either geographical proximity or similar demography.

An evidence based 5-7 year strategy (midterm) should be in place with regard to the burden of diseases with scope for periodic monitoring and review. Also, a multi-agency policy unit should be created to conduct meetings of various stakeholders for evaluation and monitoring of these studies periodically. This unit could also review current status of vaccine development and manufacturing activities in the country and also provide technical assistance in various aspects of vaccine development.

In India, the selection of vaccine for introduction in National Immunization Programme (NIP) is not a simple task. There are some standard guidelines and criteria are laid by Government of India for the introduction of new vaccine in UIP. Few criteria are: the disease should be public health problem i.e. incidence or prevalence of that particular disease, absolute number of morbidity or 
mortality epidemic or pandemic potential of that disease should be documented. The safety and efficacy of the vaccine should be given priority. One of the most important criteria is that affordability and financial sustainability should be kept in mind before introduction in NIP even if the initial introduction is supported by any external funding agency. The introducer should develop capacity for cold chain maintenance for newer vaccine and availability of a domestic or external vaccine production. Last but most important the newer vaccine should be cost effective. The grades of recommendation assessment, development and evaluation (GRADE) system is that system which shows systematic and transparent grading the quality of evidence. This GRADE strengthens the recommendations for introduction of newer vaccine.

Criteria of vaccine formulations: Many newer vaccines are there which may be considered for the introduction in UIP. But before introduction, the technical consultation of scientists, program managers, cold chain managers and representatives of the manufacturers should be taken into consideration. Also focus on, is there any alterative vaccine formulation is available or vaccines is with or without preservative, with or without adjuvant, liquid or lyophilized etc. that could enable the use of a vaccine in the existing schedule. About combination vaccine, if introducer want to introduce combination vaccines that are shown to improve coverage and reduce non-program costs and these factors that should be kept in mind before taking a decision on introduction of combined vaccines in NIP. There is NTAGI in India, which is a group of technical expert scientists which advises to government regarding the technical issues related to the vaccination and immunization. This technical group meets on a regular basis and takes various technical and policy decision related to immunization program. The term of a member of NTAGI is a minimum of 2 years which could be extended. There is sufficient interaction and discussion about immunization between members of NTAGI and international advisory experts.

In India, there is time lag from the availability of a vaccine to its use in the NIP because NTAGI performs effective, efficient and proper functioning before introduction of vaccine. Also, NTAGI follows guidelines proposed by World Health Organization- strategic advisory group of experts whether a particular vaccine can be absorbed or not, that is assessed in context to India's UIP program. NTAGI group should assess the specific situational analysis for each vaccine.

The translational research should be improved that supports the introduction of newer vaccine and NTAGI should create or revamped the capacity and infrastructure. The NTAGI group should be supported by other subgroups such as vaccine security, vaccine ethics, equity and financial sustainability for improvement on health system. The NTAGI should include other experts from the areas of public health, pediatrics, epidemiologist of infectious disease, clinicians, immunologists, medical microbiologists, cold chain experts or logisticians, statistic modelers, social scientists, drug regulators, experts in ethics, health economics, and nursing or pharmacy from the field, immunization program managers, representatives of the civil society and representation from the states Ministry of Health etc. and other members like ex-officio members from the Ministry of Health and Family Welfare. NTAGI has made it mandatory to declare conflicts of interest so that there should no bias in decision making.

Process of inclusion of a vaccine: NTAGI initially discusses the newer vaccine which is to be included in NIP. Before giving technical recommendation for introducing any newer vaccine in NIP, the experts consider the recommendations of technical committee and for implementation, operational aspects are considered by immunization division and program division. NTAGI recommended that there should be a specific work plan for vaccine that includes the existing evidence on burden of disease and efficacy of vaccine. The NTAGI also suggested that the introducer should identify data gaps and give their outline plan for collecting extra data when needed for decision making. The introduction of a new vaccine in NIP should strengthen NIP, reduce inequities, ease accessibility, increase coverage of vaccine and equitable distribution of immunization services.

Equitable distribution and ethics: The vaccine policy stresses that ethics and equity should be followed for any newer vaccine. The ethical issue and equitable distribution are the root of any program meant for ameliorating disease burden in the country. In India, this is a well-known fact that the newer vaccines are very costly and are used by upper or middle socioeconomic class children only while lower socioeconomic class children who needed utmost can't receive and they are at disadvantage of getting newer vaccine. The vaccine policy strongly recommended that any new vaccines which are being introduced in NIP should be accessible and available to the needy and poor children. The benefits of newer vaccines in children health should always outweigh the adverse effects of vaccine. The cost of vaccine and inconvenience to the parents/family should always kept in mind on top priority when you are planning. This is hard fact that there is always a problem of funding of newer vaccine in the low middle income countries. This policy should address this problem also and suggests that this issue could be solved by financing from other government agency.

Communication, information, education and advocacy: The information, education, and communication and advocacy are very important to implement any newer vaccine in the community and these are also required for acceptance and for maintaining confidence in the newer vaccines. The confidence of community on newer vaccine is required when some serious adverse events following 
immunization of new vaccine are reported. For proper implementation of newer vaccine, health care workers should be trained and retrained so that if any question raised by community or parents that should be solved immediately which in turn will maintain the confidence of parents in the vaccine. Advantage and disadvantage of giving the vaccine to the children or subject should be effectively communicated to parents or guardian.

\section{REFERENCES}

1. Puliyel J. Vaccine policy and advance market commitments. Econ Pol Wkly. 2011;46(44-45):189.

2. Bhan A. Ethical considerations in developing a national vaccine policy. Indian $J$ Med Res. 2010;132:226-7.

3. Ahmad F. U.S. Advisory Committee on Immunization Practices (ACIP) Handbook for Developing Evidence-based Recommendations. Version 1.1, National Center for Immunization and Respiratory Diseases Centers for Disease Control and Prevention (CDC) Atlanta, GA, USA; 2012: 146.

4. New initiatives help India achieve improved coverage and quality of immunization. Press Information Bureau, Government of India, Ministry of Health and Family Welfare. Available at: http://pib.nic.in/newsite/erelease.aspx?relid=73623. Accessed on 3 January 2020.

5. Madhavi Y, Puliyel JM, Mathew LJ, Raghuram N, Phadke A, Shiva M, Srinivasan S. Evidence-based National Vaccine Policy. Indian J Med Res. 2010;131:617-28.

6. Ministry of Health and Family Welfare. National Vaccine Policy April 2011. MoHFW, Government of India. Nirman Bhawan New Delhi, 2011.

Cite this article as: Verma R, Chayal V, Kalhan M, Dhaka R, Chawla S, Bhalla K. Introduction of newer vaccines in national immunization programme in India: a challenge. Int J Community Med Public Health 2020;7:1998-2000. 